\title{
Reviews on Methods of Fault Detection and Protection of Induction Motor
}

\author{
Deepak Sharma \\ Research Scholar \\ JNU, Jaipur
}

\author{
Abhishek Chaubey \\ Assistant Professor \\ JNU, Jaipur
}

\author{
Abhishek Kumar Gupta \\ Assistant Professor \\ JNU, Jaipur
}

\begin{abstract}
Fault detection for induction motors is a wide subject of research. Several fault detection methods have been developed and effectively applied to detect machine faults at different stages by using different machine variables, such as current, voltage, speed, temperature, and vibration. Induction motors are now being used more as compared to before due to their advantages such as versatility, dependability and economy, good self-starting capability, simple, rugged construction, easy maintenance, low cost and reliability. The reliability of an induction motor is of great importance in industrial, commercial, aerospace and military applications. In this review paper different problems related to over-voltage, over-current, over-temperature, over-speed, in-rush current, vibration monitoring which are faced by an Induction Motor (IM) during it course of operation are discussed. The fault detection and protection of an Induction Motor against such possible problems is carried out using Programmable Logic Controller (PLC). Induction Motor can be protected by using some components such as contactors, timers, voltage and current relays and also by using Variable frequency drive (VFD) but Programmable Logic Controller (PLC) is optimal, effective and reliable method as it does not contain any mechanical component.
\end{abstract}

\section{General Terms}

Contactors, Relays, Estimated Kalman Filter (EKF), Proportional Derivative Controller (PID).

\section{Keywords}

Programmable Logic Controller (PLC), Supervisory Control and Data Acquisition (SCADA), Variable Frequency Drive (VFD).

\section{INTRODUCTION}

The induction machine can be used as a motor as well as a generator. However, it is more frequently used as a motor. It is the workhorse of an industry. Majority of the motors used by industry are squirrel cage induction motors and both threephase and single-phase motors are widely used. An induction motor is widely used in electrical drive system and consumes more than $50 \%$ of an industry total generating capability.

A significant number of analysts have examined different sort of advances for protecting the induction motor by different methodologies. Researchers have studied a variety of machine faults and have come to a conclusion that machine failures include mechanical and electrical faults. The PLC framework is prepared with extraordinary $\mathrm{I} / \mathrm{O}$ units fitting to regulate utilization in streamlined mechanization frameworks. A large portion of conspicuous faults in the event that from claiming incitement motors, have been further more diagnosed utilizing PLC [Ravi Masand et al, 2013]. Asynchronous motor utilized as a part of electromechanical frameworks should be checked and controlled reliably amid the fabricating process in light of the way that the item quality can without much of a stretch be influenced by a breakdown of the motor [Mehmet Fatiah et al]. Pulse width modulation (or PWM) to control both the frequency and the voltage applied to the load. Without a VFD, an induction motor on start-up has to handle a high initial inrush current [M Deepa, 2015]. Due to the continuous running nature of induction motor more advanced techniques are required to properly qualify their impact. The utilization of fuzzy logic to analyze, compare \& diagnose health condition of induction motor under various faults [Chavan Mayur et al, 2013]. The method developed got a wide number of advantages in the industrial sector \& can be converted into a real time application using some interfacing cards. The design and implementation of industrial control systems often relies on quantitative mathematical models of the plants[Ashok Kushagur et al, 2009]. State estimation is method of estimating voltage magnitude and angles at all the buses of a power system from available measurements [suresh $\mathrm{j}$. Thanker et al, 2012]. The design, development \& study of protection \& supervisory control and data acquisition (SCADA) system to meet special requirements of $25 \mathrm{kV}$ AC traction system on Mumbai suburban section and essentially a computer system for gathering and analyzing real time data. SCADA systems are employed all over the world to monitor and control a plant or any equipment in various industries[Sanket kulkarni et al, 2014]. The input stage of the SMPS with the use of boostconverter-based PFC circuit and input power factor performance and efficiency of SMPS with PFC circuit will be compared to other commonly used passive circuits located at the input stage of SMPS [Taufik et al, 2007 ]. A power factor is the goal of any electrical utility company since if the power factor is less than one, they have to supply more current to the user for a given amount of power use. In so doing they occur more line losses. It can be achieved by decreasing the network losses and improving the main electric load operation to a better efficiency level [Sapna Khanchi, 2013]. Capacitor banks generate "negative" reactive power or absorb the reactive power produced by inductive loads. By using this system we can improve lagging power factor thereby system will be safe from different disadvantage of lagging power factor by use of this system the power factor control becomes very fast and accurate than other methods [Dr. Muhammad N. Khan et al]. In this proposed system the time lag between the zero voltage pulse and zero current pulse duly generated by suitable operational amplifier circuits in comparator mode are fed to two interrupt pins of the microcontroller. The program takes over to actuate appropriate number of anti-parallel SCR's at its output in series with either an inductor or a lamp or shunt capacitors into the load circuit to derive the power factor of each type of load [Monika et al, 2014]. It is possible to add too much capacitance to the system and still incur power company charges and this paper was to obtain a power factor as close to one as possible or to control the system power factor within a range that will avoid any power company charges possible. PLC is used to control of 
switching on/off capacitor bank to improve power factor[Sujit Deasai et al, 2015]. The innovation belongs in a zone far more advanced than a fan operated by a manual regulator. This device controls the speed of the induction motor used in a fan automatically by sensing the ambient temperature and It uses a TRIAC (Triode for AC) based circuitry which minimizes energy consumption and thus saves power [Rabisankar Roy et al, 2012]. Scalar controlled drives give somewhat inferior performance than the other control schemes but they are the easy to implement. In V/F control methods, the stator voltage is adjusted in a part of the supply frequency, except for low and above base speeds. At low frequency operation the voltage drop across stator resistance must be taken into account[Pabitra Kumar et al, 2014]. The benefits can be noted such as reducing the size of the control panel, very low energy consumption. The PID controller can be reduced the rise time since the proportional controller has effect on this and it can also eliminate the steady-state error by using the integral controller and lastly it can increase the stability of the system by using the derivative control[Parviz Amiri et al, 2013]. Variable Frequency Drives, speed control with full torque is achieved from $0 \mathrm{rpm}$ through the maximum rated speed and, if required, above the rated speed at reduced torque. VFDs manipulate the frequency of their output by rectifying an incoming $\mathrm{AC}$ current into $\mathrm{DC}$, and then using voltage pulsewidth modulation to recreate an $\mathrm{AC}$ current and voltage output waveform [Madvilappa et al, 2013]. Estimated Kalman Filter (EKF) is constructed to achieve a precise estimation of the speed and current from the noisy measurement. Linear Quadratic Regulator (LQR) technique is used to construct a proportional integral derivative (PID) controller to achieve the speed command tracking performance. The simulation results for the speed response and variation of the states when the PMSM is subjected to the load disturbance are presented. Kalman filter in its basic form its an state estitmator which can be used to estimate the rotor currents [Anwin John, 2014].

In the view of literature survey, following research objectives are formed for this paper.

a. In this paper discussed the various aspects and methods of fault detection and protection using PLC/SCADA, VFD and EKF.

b. After compared the different aspects of given methods, find out the most effective and reliable method of fault detection and protection, namely PLC/SCADA.

Rest part of the paper is organized as follows in section 2 block diagram, working of PLC/SCADA and its role in fault detection and protection are presented. In section 3 objectives of used method is presented last but not the least in section 4 conclusion and future scope of the work is presented.

\section{FAULT DETECTION AND PROTECTION USING VFD \& EKF}

Induction motor protection devices typically monitor the motor current and/or voltage to provide the motor protection functionalities like current overload, over/under voltage, etc. One of the interesting parameters to monitor is the operating power factor (PF) of the IM, which provides better overload protection compared to the motor current-based approaches [Abhishek Ukil, 2011]. A principal recurrence rearranged model of the VFD, which gives a satisfactory displaying to the investigation of electromechanical drifters in substantial scale control frameworks. In this the primary favorable position is that usage was done from the piece of force framework and the model was supplemented by assurance and control systems [Panasetsky D, 2016]. The impact of the VFD parameters on the level of voltage stresses influencing the protection of low-voltage acceptance engine windings and greatness of electrical worries was conveyed by building a reproduction demonstrate in the graphical programming environment Matlab Simulink [Veronika Bolgova, 2016]. Ordinary Variable Frequency Drive (VFD) strategy for enlistment engine comprises of nonlinear loads for example, rectifier and inverter (AC-DC-AC) and the greatest reason for sounds era on electrical cables. In proposed framework, detached LC channels are utilized to control the symphonious streams display on electrical cables. Sensor less speed recognition is accomplished in light of the examination of blocked voltage over the non-directing thyristors [Baitade A.T., 2016]. VFD driven engines in view of the genuine operational and wellbeing needs of the client or application, for example, engine measure, obligation cycle, driven load attributes, perilous area rating, and hardware life will be tended to [Dale Basso, 2016].

\section{FAULT DETECTION AND \\ PROTECTION USING PLC \& SCADA}

Programmable Logic Controllers also called programmable controllers. PLCs need aid strong-state parts of the machine family; utilizing incorporated circuits as opposed to electromechanical gadgets with execute control works. They need aided skill for storing instructions, for example, sequencing, timing, counting, arithmetic, information manipulation. The PLC has input lines where sensors are associated with advise upon occasions (e.g. temperature above/underneath a specific level, fluid level achieved, and so forth.), and yield lines to flag any response to the approaching occasions (e.g. begin a motor, open/close a valve etc.). Basic structural diagram of PLC is given below in Fig. 1.

[Cheatan Borse et al, 2015] has discussed about the paper about different methods for starting of the Slip Ring induction Motor. But we have opted the Rotor Resistance Control method for Starting the Induction Motor. Programming is done by using Programmable Logic Controller; control panel is designed and programmed according to requirements. PLC is used to monitor the values of the voltages, currents, temperatures, and speed of the three phase induction motor. In this discussion the frequency of PWM is kept constant since the speed of motor depends on the supply voltage frequency. In order to reduce the mechanical component's usage we prefer to use Personal Computer (PC) and Programmable Logic Controller [L Venkatsen et al, 2014]. Star Delta starting method is a motor starting mechanism that minimizes the large amount of starting current that motors draws in and it involves feeding the motor with $1 / \sqrt{3}(58 \%)$ of the full load current until it attains speed and then applying the full load current [Shruti Kharit et al, 2013]. The method of acquiring the state of the process all the time, process the information according to the set rules and guidelines, and accordingly actuating the control elements is referred to as Process Control [Sharad Chandra Rajpoot et al, 2014]. PLC based protection methods are less expensive, provide higher accuracy with safe mode of operation, compared to other protective systems. The measurement card consists of the current transformer and voltage transformer, the rotor speed is measured by an encoder, and winding temperature is measured by the temperature sensor [A.R Al-Ali et al, 2014]. 


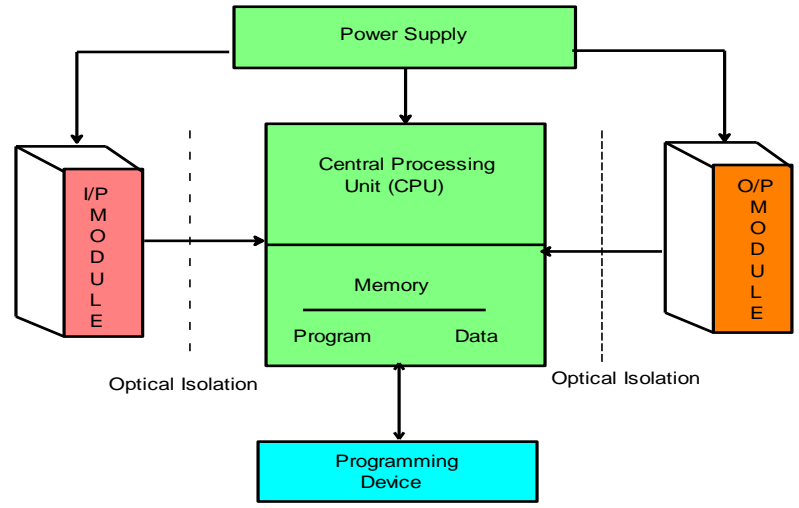

Fig. 1: Programmable Logic Controller (PLC)

\section{CONCLUSIONS}

Taking into account the various research papers discussed so far we conclude that an induction machine suffers various faults during its operation like over-voltage, over-current, over-temperature, over-speed, in-rush current etc. and these faults needs to be quickly detected so that the induction motor is protected from getting damaged. Various fault detection methods have also been discussed with their corresponding advantages and limitations. Amongst the various fault detection methods discussed so far, Programmable Logic Controller (PLC) holds an edge over other methods since it is optimal, effective and reliable method and it also does not contain any mechanical component.

\section{ACKNOWLEDGEMENTS}

The authors acknowledge the support and encouragement of Jaipur National University, Rajasthan, India.

\section{REFERENCES}

[1] Engineering, "Fault Diagnosis of Induction," pp.63476354, 2013.

[2] M. F. Işık, "Fault Detection and Protection of Induction Motor by Real Time Monitoring and Controlling of the Motor Parameters."

[3] M. Deepa, "Design of VFD Drive for a 3-Phase Induction," pp. 18755-18762, 2015.

[4] A. Electronics, "Fault detection of Induction Motor using Envelope Analysis ," vol. 2, no. 7, pp. 258-262, 2013.

[5] A. Kusagur, "Modelling of Induction Motor \& Control of Speed Using Hybrid Controller Technology," Power, p. $126,2009$.

[6] O. F. Electrical, V. Stability, and A. Of, "C i a e m e," pp. 183-191, 2012.

[7] S. Kulkarni, "A Review of SCADA Systems in Indian Railways," vol. 3, no. 11, pp. 818-822, 2014.

[8] A. Hernadi, R. Rudianto, and M. Anwari, "Performance Study of Power Factor Correction Circuits," pp. 419422, 2007.

[9] S. Khanchi, V. K. Garg, and P. Vi, "Power Factor Improvement of Induction Motor," vol. 4, no. 7, pp. 2967-2971, 2013.

[10] A. Hayat and M. N. Khan, "Speed Control and Power Factor Improvement of a Single Phase AC Motor," vol. 2 , no. 8, pp. 328-336, 2014.
[11] G. Deivanayaki, "Power Factor Correction Using Integrated UPFC for Induction Motor," vol. 1, no. 1, 2014.

[12] S. Desai, N. Lalpurwala, and V. Salokhe, "Power Factor Correction for 1 Phase Induction Motor Using PLC," vol. 3, no. 2, pp. 3-6, 2015.

[13] R. Roy, S. Das, J. K. Ray, S. Barat, and B. Neogi, "Automatic Speed Control of Single Phase Induction Motor with the Variation of Ambient Temperature," vol. 2, no. 11, pp. 11-14, 2012.

[14] P. K. Behera, "Speed Control of Induction Motor using Scalar Control Technique," pp. 37-39, 2014.

[15] P. Amiri and M. Bagger, "Speed Control of DC Motor by Programmable Logic Control with High Accuracy," Univers. J. Control Autom., vol. 1, no. 4, pp. 91-97, 2013.

[16] R. Khemchandani, A. N. Singh, and H. Khanna, "Speed Control of Three Phase Induction Motor by Variable Frequency Drive," Int. J. Res., vol. 1, no. 11, pp. 157 158, 2014.

[17] A. John, "Speed and Current Observer for Induction Motor using Extended Kalman Filter," vol. 3, no. 7, pp. 962-965, 2014

[18] C. Borse and A. Pandhare, "Plc based induction motor starting and protection," vol. 3, no. 2, pp. 893-897, 2015.

[19] V. Loganathan, S. Kanagavalli, P. R. Aarthi, and K. S. Yamuna, "PLC SCADA Based Fault Identification and Protection for Three Phase Induction Motor," TELKOMNIKA Indones. J. Elect. Eng., vol. 12, no. 8, pp. 5766-5773, 2014.

[20] S. Kharait and P. S. Phulambrikar, "Implementation of PLC Based Star Delta Starter for Starting and Direction Control Of Three Phase Induction Motor," vol. 2, no. 11, pp. 2881-2886, 2013

[21] M. T. Scholar, "A Typical PLC Application in Automation," vol. 3, no. 6, pp. 498-502, 2014.

[22] A. R. Al-Ali, M. M. Negm, and M. Kassas, "A PLC based power factor controller for a 3-phase induction motor," Conf. Rec. 2000 IEEE Ind. Appl. Conf. ThirtyFifth IAS Annu. Meet. World Conf. Ind. Appl. Electrical Energy (Cat. No.00CH37129), vol. 00, no. C, pp. 10651072, 2000

[23] A. Ukil, S. Member, R. Bloch, and A. Andenna, "Estimation of Induction Motor Operating Power Factor From Measured Current and Manufacturer Data," pp. 18,2010 .

[24] D. Basso and P. Shah, "SPECIFYING VFD DRIVEN LOW VOLTAGE MOTORS FOR SAFETY AND,” pp. $1-6$.

[25] A. T. Baitade, "Harmonic Reduction, Power Factor Improvement and Speed Detection for 3-Phase Induction Motor Drive System” pp. 406-411, 2016.

[26] V. Bolgova, A. Leonov, and D. Charkov, "Influence of VFD Parameters on Voltage Stresses in Low Voltage Windings" 2016.

[27] D. Sidorov and A. Osak, "Simplified variable frequency induction-motor drive model for power system stability studies and control," IFAC-Papers On Line, vol. 49, no. 27, pp. 451-454, 2016. 